\title{
The Role of Cathepsin B in Ischemia- Reperfusion Injury After Stroke
}

\author{
Bhakta Prasad Gaire • Lalita Subedi • Hironori Teramoto • Bingren Hu \\ Department of Anesthesiology and Neurology, Shock Trauma and Anesthesiology \\ Research Center, University of Maryland, School of Medicine, Baltimore, MD, USA
}

Author for correspondence: Bingren $\mathrm{Hu}$, Department of Anesthesiology and Neurology, Shock Trauma and Anesthesiology Research Center, University of Maryland, School of Medicine, Baltimore, MD, USA. Email: bhu@som.umaryland.edu

Cite this chapter as: Gaire BP, Subedi L, Teramoto H, Hu B. The Role of Cathepsin B in Ischemia-Reperfusion Injury After Stroke. In: Pluta R, editor. Cerebral Ischemia. Brisbane (AU): Exon Publications; 2021. Online first Sep 10.

Doi: https://doi.org/10.36255/exonpublications.cerebralischemia.2021.cathepsin

\begin{abstract}
Cathepsins are endolysosomal proteases that can be categorized into different types based on their structures and active-site amino acid residue, including cysteine (cathepsins B, C, F, H, K, L, O, S, V, W, and X), serine (cathepsins A and $\mathrm{G}$ ), and aspartic (cathepsins $\mathrm{D}$ and $\mathrm{E}$ ). Cathepsins can regulate diverse cellular activities such as the processing and presentation of antigens, the processing and activation of hormones, apoptosis, aging, and autophagy. Recently, cathepsin $\mathrm{B}$ has gained attention for its role in various neurological diseases including ischemic stroke, Alzheimer's disease, Parkinson's disease, and traumatic brain injury. This chapter mainly focuses on the role of cathepsin B in brain ischemiareperfusion injury in animal models of stroke.
\end{abstract}

Keywords: cathepsin B; cerebral ischemia; cysteine proteases; neurodegeneration; neuroinflammation

In: Cerebral Ischemia. Pluta R (Editor). Exon Publications, Brisbane, Australia. ISBN: 978-0-6450017-9-2; Doi: https://doi.org/10.36255/exonpublications. cerebralischemia.2021

Copyright: The Authors.

License: This open access article is licenced under Creative Commons Attribution-NonCommercial 4.0 International (CC BY-NC 4.0) https://creativecommons.org/licenses/by-nc/4.0/ 


\section{INTRODUCTION}

Ischemic stroke is one of the leading causes of death and disability worldwide. The World Health Organization (WHO) defines stroke as "rapidly developing clinical signs of focal (or global) disturbance of cerebral function lasting more than $24 \mathrm{~h}$ or leading to death with no apparent cause other than a vascular origin" (1). Stroke can be categorized as of ischemic, hemorrhagic, or subarachnoid types. Most strokes (87\%) are ischemic strokes (2).

Ischemic stroke is a sudden interruption of the blood supply to a part of the brain, also known as focal ischemia. After ischemic stroke, oxygen and glucose deprivation leads to energy failure or adenosine triphosphate (ATP) depletion in the ischemic region. The ATP depletion, if long enough, triggers numerous pathophysiological events, such as membrane depolarization, glutamate release, sodium and calcium influx, subcellular organelle damage, and eventually leads to tissue necrosis $(3,4)$. After focal ischemic stroke, about $80 \%$ of neurons die in the nonperfused core with complete ischemia within 4 hours, whereas about $40 \%$ of neurons gradually die in the hypo-perfused penumbral region over a period of 4 to 24 hours (5). The breakdown of the blood-brain barrier (BBB), microglia activation, monocyte/neutrophil infiltration, and astrogliosis are just observed until 24 hours after focal brain ischemia (5).

Several decades of research have proven that post-ischemic tissue within a certain period can be rescued by restoring the blood supply to the ischemic territory, i.e., reperfusion, as shown clinically with Alteplase (tPA) and endovascular reperfusion treatments that may improve clinical outcomes. However, reperfusion can also inadvertently lead to ischemia-reperfusion injury (6). The events related to brain ischemia-reperfusion injury may include glutamate excitotoxicity, calcium overload, cellular and endoplasmic reticulum (ER) stress responses, mitochondrial dysfunction, overproduction of reactive oxygen species, protein misfolding and aggregation, dysfunctional autophagy and endolysosomal system, dysfunctional ubiquitin and proteasomal system, activation of numerous intracellular signaling pathways, breakdown of the BBB, expression of adhesion molecules and leukocyte adhesion, and post-ischemic local and systemic inflammation (7-11).

The role of the post-ischemic breakdown of the BBB, microglia activation, monocyte/neutrophil infiltration, and astrogliosis in stroke brain injury have been intensively studied recently. The infiltration of inflammatory and immune cells is involved in the cleanup of post-ischemic tissue and cell debris but may also release neurotoxic mediators causing progression of stroke brain injury $(12,13)$. The activation of brain resident glial cells has been considered as a double-edged sword in the modulation of ischemic events. On one hand, activated microglia and astrocytes are involved in ischemic recovery through their promotion of anti-inflammatory responses, neurogenesis, angiogenesis, and synaptogenesis in the post-ischemic brain $(14,15)$. On the other hand, these cells produce proinflammatory cytokines, chemokines, reactive oxygen species, etc., which could contribute to progression of stroke brain injury $(14,15)$. Therefore, understanding the post-stroke local and systemic inflammatory and immune responses could facilitate the development of ischemic stroke therapies. 


\section{CATHEPSINS}

A protease (also called a peptidase or proteinase) is an enzyme that catalyzes proteolysis, the breakdown of proteins into smaller polypeptides or single amino acids. They do this by cleaving the peptide bonds by hydrolysis. Proteases are generally classified as endo- and exo-peptidase depending upon the peptide bond locations to be cleaved. Proteases can be further classified into serine, cysteine, and aspartic proteases and metalloproteases. Exo-peptidases consist of aminopeptidases and carboxypeptidases. In the normal brain, proteases play a key role in the catabolism of cellular and extracellular proteins including peptide neurotransmitters, intracellular signaling proteins, cellular structural proteins, and extracellular matrix proteins (16). Abnormal protease activities have been implicated in the pathogenesis of a diverse number of acute brain injuries such as ischemic stroke and traumatic brain injury, and all types of chronic neurodegenerative disorders (17). For instance, activation of matrix metalloproteinases (MMPs) may play a role in the BBB breakdown after stroke $(18,19)$. Activation of calpain may lead to ischemia-reperfusion brain injury (20). Activation of caspases may lead to cell apoptosis after stroke (21). Recently, cathepsins have been in the spotlight because of their role in regulating autophagy, phagocytosis, apoptosis, and inflammation commonly observed in brain tissue after stroke. Cathepsins also play a key role in various central nervous system (CNS) disorders. Therefore, the strict regulation of their activities is necessary to maintain tissue or cellular homeostasis.

Cathepsins are primarily located in the lumen of endolysosomal structures and are abundantly found in all organisms (22). Cathepsins are classified into cathepsin A, B, C, D, E, F, G, H, K, L1, L2, O, S, V, W, and Z. Most cathepsins function inside endolysosomal compartments (mostly late endosome and endolysosome) for degradation of cellular waste cargos, but with a few exceptions. Cathepsins B and $\mathrm{K}$ also play a role in extracellular signaling and extracellular matrix remodeling (23). Some cathepsins can be released from the endolysosomal compartments into the cytosol to initiate a variety of intracellular events. For example, a small amount of intracellularly released cathepsins (cathepsins B, C, L, S and Z) can induce the activation of inflammasomes and apoptosis (24). Cathepsins can be secreted outside of cells (25), where they can either remain attached to the cell membrane or be released into the extracellular space. Cathepsins attached to the plasma membrane can cleave membrane protein extracellular domains like integrins or membrane receptors, whereas extracellular cathepsins are involved in the degradation of the extracellular matrix proteins $(22,24,26,27)$. Cathepsins can also be involved in the recruitment of immune and vascular cells towards the site of injury in cardiovascular diseases $(28,29)$ and brain ischemia $(30,31)$. In addition, cathepsins may play a role in specific tissues. For instance, cathepsin $\mathrm{K}$ is predominantly secreted by activated osteoclasts to degrade collagen and other matrix proteins during bone resorption (32).

\section{CATHEPSIN B}

Among others, cathepsin B (CTSB hereafter), is considered as a potential drug target for several human ailments including various cancers (33-35), 
rheumatoid arthritis $(36,37)$, liver fibrosis (38), pancreatitis (39), and microbial infection (40-42). Additionally, CTSB has been shown to play a role in stroke (43-46), traumatic brain injuries, epilepsy, Alzheimer's disease, Parkinson's disease, and multiple sclerosis (47-54). Most cathepsins solely have endopeptidase activity, while CTSB has both endopeptidase and exopeptidase activity (55). Notably, CTSB is the most abundant cathepsin in the brain (56). CTSB is synthesized on ER-associated ribosomes as a pre-proenzyme of 339 amino acids. While being synthesized, pre-procathepsin B is imported into the ER lumen. After synthesis, CTSB is cleaved by a signal peptidase inside the ER lumen to become proCTSB (46 kDa) (57). This proCTSB is glycosylated with high levels of mannose within the ER before being transported via ER-derived transport vesicles to the Golgi apparatus. In the Golgi, the mannose residues are modified to become mannose-6-phosphate (M6P) moieties. The M6P-tagged proCTSB and its associated M6P-receptors (M6PR) are packed together into clathrincoated vesicles and transported to the late endosomes (23). Once in the late endosomal acidic environment, M6PR releases the M6P-proCTSB and is transported back to the trans-Golgi network to be reused (58). Inside the late endosomal acidic environment ( $\mathrm{pH}$ 6.0), the propeptide of proCTSB undergoes autocleavage or is cleaved by other cathepsins to remove the 62-amino acid propeptide from the $\mathrm{N}$-terminus and the 6 amino acids from the $\mathrm{C}$-terminus to become a 31-33 kDa mature single chain CTSB. The CTSB maturation continues after the late endosome fuses with a terminal lysosome to become an endolysosome where the $31-33 \mathrm{kDa}$ mature single chain form of CTSB is further processed into its $24-27 \mathrm{kDa}$ double heavy chain form and a $5 \mathrm{kDa}$ light chain which are linked by disulfide bonds (Figure 1) $(9,57,59)$. Enzymatic deglycosylation reveals that the $27 \mathrm{kDa}$ polypeptide is the glycosylated variant of the carbohydrate-free $24 \mathrm{kDa}$ heavy-chain form (58). The 24-27 kDa double heavy chain CTSB is proteolytically active (60).

\section{CTSB AND ENDOLYSOSOMAL TRAFFICKING}

As described above, CTSB undergoes continuous transformations through a series of subcellular organelles of the ER, Golgi and endolysosomal trafficking systems. The endolysosomal system comprises the extension of the trans-Golgi biosynthetic pathways, autophagic pathways, and endocytic (early endosome to late endosome) pathways. In this chapter, the endolysosomal system refers to the gamut of endolysosomal compartments or structures comprising the late endosome, endolysosome, and terminal lysosome (Figure 1) $(23,61)$. These three endolysosomal structures contain almost identical protein compositions. The late endosome has been considered as the precursor of the endolysosome and lysosome. For that reason, the commonly used lysosomal markers such as cathepsins and lysosomal membrane-associated proteins are major components of the late endosome, endolysosome, and lysosome. There are no specific protein markers that can differentiate the late endosome from the endolysosome (62). M6PR and Rab7 (ras-related protein rab-7) are the only two proteins currently known to be present in the late endosome and endolysosome but absent in the terminal lysosome (63). 

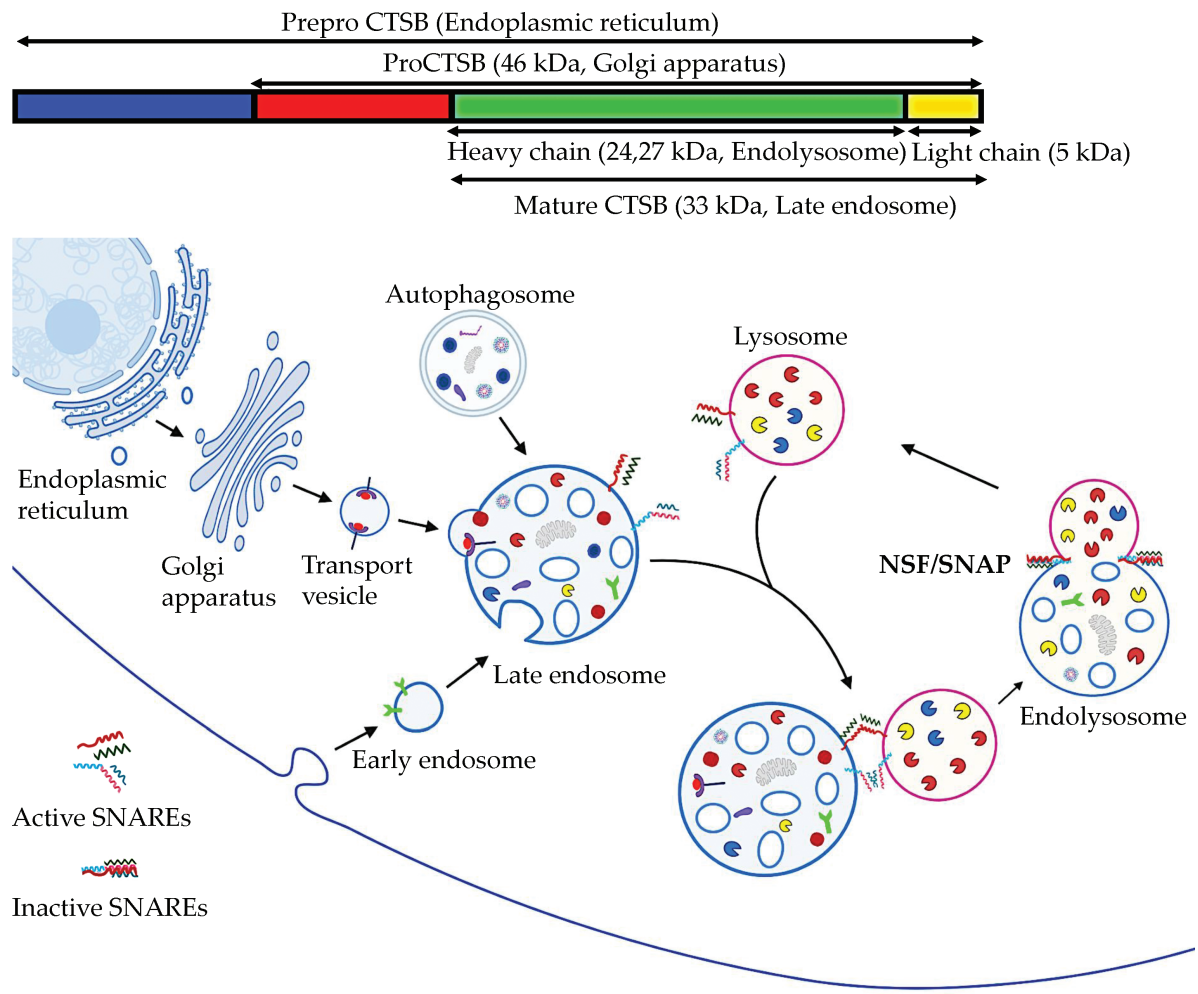

Figure 1. Cathepsin B intracellular trafficking. CTSB is originally synthesized as a preproenzyme in the ER-associated polyribosome. Upon translocation to the ER, CTSB pre-peptide is cleaved to form a $46 \mathrm{kDa}$ form of proCTSB and then glycosylated before being transported into the Golgi apparatus. The proCTSB in the Golgi apparatus is then transported via transport vesicles to the late endosome where the pro-peptide is cleaved to form a $33 \mathrm{kDa}$ single chain form of mature CTSB. After late endosomal fusion with a lysosome to become an endolysosome, the $33 \mathrm{kDa}$ single chain form of mature CTSB is further cleaved to a 24-27 kDa double heavy chain form of CTSB. Membrane fusion between late endosome and lysosome is mediated by the NSF-SNAP-SNAREs machinery. After fusion, active SNAREs become inactive complexes and must be dissociated or reactivated by the cooperative action of NSF ATPase and SNAP for the next round of membrane fusion.

All endolysosomal compartments have acidic lumens, which is maintained by their transmembrane proton pump, i.e., vacuolar ATPase (V-ATPase) (64). Different densities of V-ATPase are present throughout the endolysosomal compartments to create a $\mathrm{pH}$ range from 6.0 in the late endosome to 4.5 in the lysosome (65). Although the late endosome receives incoming acid hydrolytic enzymes from the Golgi apparatus and degradation cargos from the early endosome and autophagosome, they cannot degrade these waste cargos efficiently because of their higher intraluminal $\mathrm{pH}$ (6.0). They must be acidified by fusing with the more acidic terminal lysosome ( $\mathrm{pH} 4.5)$ to become a hybrid endolysosome (23). The endolysosome is the principal intracellular site of acid hydrolase activity for degradation of early endosomal and autophagic 
cargos, whereas the terminal lysosome acts as a store of acid hydrolases and is cathepsin-inactive (23). After degradation of the cargo, an endolysosome reforms into a new terminal lysosome, which is ready to fuse with another late endosome and participate in the next round of the endolysosome-terminal lysosome cycle (23).

The fusion between late endosome and terminal lysosome is facilitated by the cooperative action of a few protein complexes. The core proteins for endolysosomal fusion include: (i) N-ethyl-maleimide sensitive factor (NSF), (ii) soluble NSF attachment protein (SNAP), and (iii) soluble NSF attachment protein receptors (SNAREs) (66). SNAREs are fusion proteins and can be divided into vesicle or v-SNAREs, and target or t-SNAREs. Interactions between $\mathrm{v}$ - and t-SNAREs from two opposite lipid membranes form transSNARE complexes, bringing two membranes nearby for their phospholipid membranes to merge into a single organelle. After fusion, SNAREs form inactive stable complexes and must be dissociated by NSF ATPase to become the individual active conformations for the next round of membrane fusion (67, 68). This reactivation requires SNAREs to connect the NSF ATPase via an adaptor protein SNAP $(67,68)$.

Mutation of the aminoacid 329 glutamate of NSF with glutamine (termed E329Q mutation) leads to complete cellular NSF ATPase inactivation via a dominant-negative mechanism (69). Expression of E329Q NSF dominant negative mutant in cell cultures leads to NSF deposition into two major subcellular organelle systems: (i) the Golgi apparatus, and (ii) the endolysosomal system (70). Meanwhile, other subcellular structures such as the ER are minimally affected by NSF inactivation in cell cultures (70). Therefore, NSF inactivation preferentially damages the Golgi apparatus and endolysosomal systems (70). The Golgi and endolysosomal structures are the major membrane trafficking organelles containing the highest amount of NSF, SNAP, and SNARE proteins (70). In comparison, other subcellular organelles such as ER membranes recruit only a little amount of NSF despite the known ability of SNAREs to bind $\alpha$-SNAP and NSF in these subcellular organelles (70). For that reason, the Golgi apparatus and endolysosomal systems depend on NSF-mediated membrane fusions to maintain their normal structures and functions, whereas the rest of subcellular organelles have a minimal requirement of a functional NSF-SNAP-SNARE machinery to support their normal structures (70). This conclusion is further supported by NSF knockdown studies. Knockdown of NSF in the normal immortalized human kidney cells primarily results in a large-scale buildup of late endosomes, which can be visualized under confocal microscopy, as well as various endolysosomal structures containing whole organelles, membrane whorls, and electron-dense aggregates, that can be seen under electron microscopy (70).

Ischemic stroke injury leads to the inactivation of neuronal NSF ATPase (46). As a result, the Golgi apparatus is irreversibly fragmented, and the endolysosomal structures are massively increased in both size and number in post-ischemic neurons $(9,46)$. This massive buildup of Golgi apparatus fragments and endolysosomal structures eventually leads to their structural damage and the release of CTSB causing a progression of stroke brain injury (46). 


\section{THE ROLE OF CTSB IN NEURONAL DEATH AND INFLAMMATION}

Cytoplasmic CTSB released from neuronal endolysosomal compartments may activate the Bax-like BH3 protein (Bid) and the Bcl-2-associated X protein (Bax) pathway, resulting in induction of mitochondrial outer membrane permeabilization (MOMP) after brain ischemia (71). Both Bid and Bax are expressed in mature neurons (72). The full-length Bid protein does not expose its mitochondrial anchoring segment and is inactive in the cytosol of healthy cells. Moderately released CTSB cleaves the Bid autorepression domain to produce active truncated Bid (tBid), resulting in tBid translocation to the mitochondrial outer membrane. tBid then induces oligomerization of Bax to form mitochondrial outer membrane pores. As a result, MOMP is induced, leading to cell death (71).

MOMP has been detected in several paradigms of neuronal death and is commonly considered as the 'point of no return' (71). A distinctive sign of MOMP is the cytosolic release of proteins such as cytochrome $C$ (CytC), apoptosis inducing factor, endonuclease $G$, and high temperature requirement protein A2 (Htra2) from the intermembrane space between the inner and outer mitochondrial membranes (73-76). CTSB-dependent Bid cleavage, as well as tBid and Bax translocation to mitochondria have been observed in in vivo and cell culture studies $(45,77,78)$. Extensive CTSB release, however, can digest proteins indiscriminately to directly induce tissue infarction (79).

The cytoplasmic CTSB outside of endolysosomal compartments has been detected in neurons after global brain ischemia (44). New evidence supports that a microscale amount of CTSB is released from mildly damaged endolysosomal compartments after global brain ischemia $(9,80)$. This microscale CTSB release may be limited inside of neurons to cause a non-rupture type of cell death via the MOMP as described above after a brief episode of global brain ischemia $(9,80)$. When compared to a brief episode of global brain ischemia (10-15 min), prolonged focal brain ischemia (e.g., 1-2 hours) results in a more significant release of CTSB (81). A recent report suggested that CTSB was released on a large scale from substantially damaged endolysosomal compartments into the cytoplasm and eventually into the extracellular space (81). This large-scale CTSB release causes direct tissue infarction (81).

The early release of CTSB occurs in post-ischemic neurons particularly into the cytoplasm, which could happen due to endolysosomal structural damage (45). A discrete small punctate immunolabeling pattern of CTSB was seen in the cytoplasm of normal brain neurons (82). However, after brain ischemia, CTSBimmunostained cytoplasmic structures were enlarged, became more numerous, and also showed diffuse intracellular distribution as early as at 30 min of reperfusion (83) and remained elevated for at least $24 \mathrm{~h}$ in post-stroke neurons $(9,46)$. CTSB also leaked into the neuronal cytosol of the ischemic core region during a period of $1-4 \mathrm{~h}$ of reperfusion after 1 hour of middle cerebral artery occlusion (MCAO), suggesting that endolysosomal membrane integrity was rapidly lost in the post-ischemic core neurons (45). In addition, the CTSB levels significantly increased in post-ischemic neurons in the ischemic core region at 1 hour and 
12 hours post-reperfusion after MCAO in rats (43). Similarly, increased CTSB immunoreactivity was detected exclusively in the penumbral neurons at two hours of reperfusion following 2-hour MCAO in rats (84). The immunoreactivities of CTSB, cathepsin $\mathrm{H}$, and cathepsin L were significantly increased in the hippocampal CAl pyramidal neurons after transient global brain ischemia in the gerbil and monkey models (85). These studies suggest that the level of CTSB is increased in post-ischemic neurons during the early phase (1-24 h) in different animal models.

The level of CTSB is also upregulated in cell types other than neurons in the late post-ischemic phase (1-30 days) in animal brain ischemia models (86-88). CTSB immunolabeling showed a significant upregulation in reactive microglial cells and infiltrated inflammatory immune cells from 2-3 days of reperfusion onward until a couple of weeks after stroke $(87,88)$. CTSB is a key regulator of inflammation in non-neuronal cells after stroke (86). Typically, in a normal brain, neurons show a high level of CTSB, whereas non-neuronal cell types such as astrocytes, microglia, oligodendrocytes, and blood vessel cells display a relatively low level of CTSB, consistent with the observations that CTSB was barely detectable in the non-neuronal cell types under confocal microscopy $(9,89)$. However, the protein level of CTSB was upregulated on a large-scale in the activated microglia, macrophage, cytotoxic $\mathrm{T}$ cells, and other infiltrated inflammatory cells during the late (from $24 \mathrm{~h}$ onward) post-ischemic phase (89). The CTSB protein level continuously increased during the first week after injury in a rat contusion-injured spinal cord model (90). In addition, peripheral inflammatory and immune cells, such as macrophages and cytotoxic T cells also expressed higher levels of CTSB in the epicenter of the injured spinal cord (89). These studies suggest that the upregulation of CTSB in peripheral inflammatory and immune cells might facilitate their infiltration into the brain injury area after stroke.

Post-stroke activation of glial cells is a key part of neuroinflammation (11, 91, 92). Microglial CTSB may play a key role in neuroinflammatory brain diseases and brain aging for the following reasons (47). Microglial CTSB is involved in the production and secretion of proinflammatory cytokine interleukin-1 $\beta$ through pyrin domain-containing protein 3 inflammasome-independent processing of procaspase-3 in the phagolysosomes (47). Microglial CTSB may regulate nuclear factor kappa-light-chain-enhancer of activated B cells (NF-kB) transcriptional

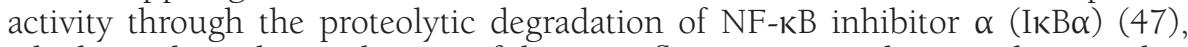
which regulates the production of diverse inflammatory mediators. These studies demonstrate that CTSB plays a role in the activation of microglial cells after brain ischemia. However, it is essential to dissect the role of CTSB in neuronal injury from that in the inflammatory response after brain ischemia. The potential role of CTSB in stroke brain injury is summarized in Figure 2.

\section{INHIBITION OF CTSB AFTER ISCHEMIC STROKE}

CTSB inhibitors have been used to study brain protection against ischemic brain injury in animal models. Gu and colleagues showed that treatment of rats with a CTSB inhibitor 2-(3',5'-Dimethoxybenzylidene) cyclopentanone (DMBC) at 1 or 6 hours after permanent MCAO reduced brain infarction and neurological 
A

\section{Post-stroke neuronal cells}

\section{Endolysosomal CTSB}

Degrades protein aggregates, damaged organelles, and endocytic cargos to maintain cellular homeostasis

\section{Cytoplasmic CTSB}

Cleaves Bid to generate tBid to induce MOMP and the release of $\mathrm{CytC}$, endonuclease $\mathrm{G}$, and Htra2, causing cell death

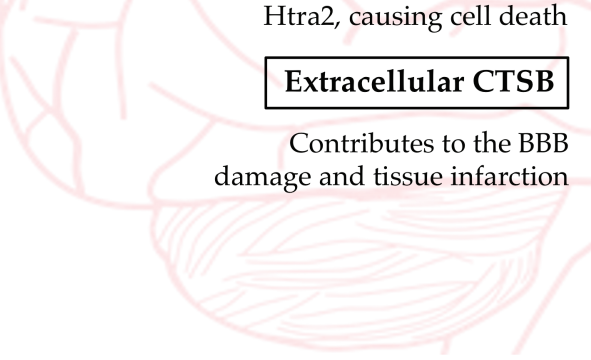

\section{B}

\section{Post-stroke Non-neuronal cells}

\section{Microglial CTSB}

Participates in phagocytotic activities to remove dead cells and tissue debris

\section{Infiltrated cell CTSB}

Facilitates infiltration and migration of inflammatory and immune cells into injured brain tissue.

Figure 2. The role of CTSB in neurons and non-neuronal cells after ischemic stroke. A, Poststroke neurons require functional cathepsins including CTSB inside the endolysosomal compartments for the removal of protein aggregates, damaged organelles, and endocytic cargos to maintain intra-neuronal homeostasis. However, when released into the cytoplasm, CTSB can cleave Bid to generate $\mathrm{tBid}$ causing MOMP and the release of $\mathrm{CytC}$, endonuclease $\mathrm{G}$, and Htra2. The cytoplasmic CTSB-induced cascade of events that eventually contributes to cell death. When released from the damaged neurons into the extracellular space in a large quantity, CTSB can directly damage the BBB and lead to tissue infarction. B, In post-stroke microglial cells and infiltrated inflammatory and immune cells (macrophages and cytotoxic $T$ cells), the endolysosomal compartments are required for the phagocytotic activities to remove dead cells and injured tissue to maintain tissue homeostasis. Macrophages secrete CTSB to infiltrate into brain damaged areas after stroke, thus contributing to tissue remodeling or damage.

deficits (93). Seyfried et al. showed that treatment of rats with cysteine protease inhibitor (CP-1) at 2 hours after MCAO reduced brain infarction and functional deficits (94). Furthermore, post-ischemic treatment with CP-1 reduced infarct volume, neurological deficits, and CTSB activity in the brain in the rat hemorrhagic stroke model (95). Seyfried et al. also demonstrated that continuous intraventricular infusion of stefin A, a CTSB inhibitor, before 2-hours of MCAO significantly reduced infarct volume (84).

Zuo et al. showed that treatment of rats with bis(propyl)-cognitin (B3C) attenuated the number of CTSB positive cells and protein expression levels of CTSB in the ventral posterior nucleus of the ipsilateral thalamus and decreased tissue damage after distal MCAO (96). Gauthier et al reported that treatment with cystatin C, an indigenous cysteine protease inhibitor, offered neuroprotection in diverse 
neurological disorders including stroke (97). Focal brain hypoxia was shown to cause extensive hippocampal tissue injury in neonatal wild-type mice, but not in CTSB knockout mice (98).

It is noteworthy to mention that although several studies have demonstrated that treatment with CTSB chemical inhibitors such as CA-074Me and E64d might offer brain protection in animal ischemic stroke models, these studies should be interpreted with caution for the following reasons. Treatments of animals with chemical CTSB inhibitors increase endolysosomal concentration by about 3-fold due to inhibition of normal endolysosomal activity and CTSB turnover rate (54, 99). Most chemical cathepsin inhibitors, including CA-074 and CA-074Me, are actually not specific for CTSB, despite manufacturer's claims (100-102). Also, the effects of some CTSB inhibitors occur primarily at a pH between 4.5-5.0 and are ineffective at a neutral pH of 7.4 (103). The endolysosomal luminal (pH 4.5-5.0) CTSB activity is beneficial in degrading protein aggregates and damaged organelles, while the released CTSB activity outside the endolysosomal lumen is harmful after stroke $(46,79)$. Therefore, some chemical inhibitors prevent natural endolysosomal degradation activities from occurring and thus might even result in more cell damage after brain ischemia. At the same time, these chemical inhibitors have a limited effect on the harmful CTSB activity at neutral $\mathrm{pH}$ outside of the endolysosomal lumen. An ideal inhibitor would limit its inhibitory activity to the harmful released CTSB while having no impact on the endolysosomal luminal degradation activities.

\section{CONCLUSION}

After ischemic stroke, neuronal necrosis occurs during the early phase, mostly within 1-24 hours (5). In comparison, microglia activation, monocyte/neutrophil infiltration, and astrogliosis takes place mainly from 24 hours onward after stroke $(5,11,104)$. CTSB trafficking in neurons is significantly impeded during the early post-stroke phase, resulting in CTSB release from the neuronal endolysosomal compartments causing progression of stroke brain injury $(46,79)$. The CTSB level is significantly upregulated in the endolysosomal compartments in non-neuronal cells from 24 hours onward after stroke. As schematically illustrated in Figure 2, CTSB may play a multidimensional role in neurons and non-neuronal cells, inside and outside of endolysosomal compartments after stroke.

Brain ischemia leads to a massive buildup of protein aggregates and damaged organelles in post-ischemic neurons $(4,46,105,106)$. To maintain tissue and cellular homoeostasis, post-stroke neurons require functional cathepsins including CTSB inside the lumen of the endolysosomal compartments to degrade endocytic and autophagic cargos overproduced after brain ischemia (Figure 2A). Therefore, the endolysosomal luminal cathepsins should not be inhibited after brain ischemia. However, when released into the cytoplasm, CTSB can cleave Bid to generate truncated Bid (tBid) causing MOMP and the release of $\mathrm{CytC}$, endonuclease $\mathrm{G}$, and $\mathrm{Htra2}$ from the mitochondrial intermembrane/intercristae spaces (73-76) (Figure 2A). The cytoplasmic CTSB-induced cascade of events will eventually contribute to cell death (71). CTSB, when released from the damaged neurons into the extracellular space in a large quantity, can digest proteins 
indiscriminately to directly damage the $\mathrm{BBB}$ and lead to tissue infarction (79) (Figure 2A).

The CTSB level is significantly upregulated in non-neuronal cells, particularly infiltrated macrophages, in the injured brain region after stroke. The upregulation of CTSB and the endolysosomal system in inflammatory and immune cells is needed for phagocytosis of post-ischemic damaged tissues to maintain the tissue homeostasis (107) (Figure 2B). However, when released into the cytoplasm from endolysosomal compartments of microglial or other inflammatory cells, CTSB can mediate the formation of nucleotide-binding oligomerization domain-like receptor and pyrin domain-containing protein 3 (NLRP3) inflammasome and activate caspases 1 to cleave and activate proinflammatory cytokines (e.g., interleukin [IL]-1 $\beta$, IL-18, etc.) (107). Similarly, macrophage and other inflammatory cells secrete a fair amount of CTSB to facilitate their infiltration and migration into injured tissues to degrade extracellular matrix (ECM) proteins or even to cause tissue damage (98). Therefore, understanding the multidimensional role that CTSB plays in neurons and non-neuronal cells, inside and outside of endolysosomal compartments, and during the early and late phases after ischemic stroke may facilitate the development of corresponding strategies for the treatment of stroke.

Acknowledgements: This work was supported by National Institutes of Health (NIH) grants: NS097875, NS102815; by Veteran Affair Merit grant: BX003926 to B.R.H.

Conflict of Interest: The authors declare no potential conflict of interest with respect to research, authorship, and/or publication of this manuscript.

Copyright and Permission Statement: The authors confirm that the materials included in this chapter do not violate any copyright laws.

\section{REFERENCES}

1. Aho K, Harmsen P, Hatano S, Marquardsen J, Smirnov VE, Strasser T. Cerebrovascular disease in the community: results of a WHO collaborative study. Bull World Health Organ. 1980;58(1):113-30.

2. Writing Group M, Mozaffarian D, Benjamin EJ, Go AS, Arnett DK, Blaha MJ, et al. Heart Disease and Stroke Statistics-2016 Update: A Report From the American Heart Association. Circulation. 2016;133(4):e38-360.

3. Choi DW, Rothman SM. The role of glutamate neurotoxicity in hypoxic-ischemic neuronal death. Annu Rev Neurosci. 1990;13:171-82. https://doi.org/10.1146/annurev.ne.13.030190.001131

4. Pluta R, Salinska E, Puka M, Stafiej A, Lazarewicz JW. Early changes in extracellular amino acids and calcium concentrations in rabbit hippocampus following complete 15-min cerebral ischemia. Resuscitation. 1988;16(3):193-210. https://doi.org/10.1016/0300-9572(88)90046-9

5. Fifield KE, Vanderluit JL. Rapid degeneration of neurons in the penumbra region following a small, focal ischemic stroke. Eur J Neurosci. 2020;52(4):3196-214. https://doi.org/10.1111/ejn.14678

6. Nour M, Scalzo F, Liebeskind DS. Ischemia-reperfusion injury in stroke. Interv Neurol. 2013;1(3-4): 185-99. https://doi.org/10.1159/000353125

7. Ricke KM, Pass T, Kimoloi S, Fahrmann K, Jungst C, Schauss A, et al. Mitochondrial Dysfunction Combined with High Calcium Load Leads to Impaired Antioxidant Defense Underlying the Selective 
Loss of Nigral Dopaminergic Neurons. J Neurosci. 2020;40(9):1975-86. https://doi.org/10.1523/ JNEUROSCI.1345-19.2019

8. Jiang X, Andjelkovic AV, Zhu L, Yang T, Bennett MVL, Chen J, et al. Blood-brain barrier dysfunction and recovery after ischemic stroke. Prog Neurobiol. 2018;163-164:144-71. https://doi.org/10.1016/j. pneurobio.2017.10.001

9. Yuan D, Liu C, Hu B. Dysfunction of Membrane Trafficking Leads to Ischemia-Reperfusion Injury After Transient Cerebral Ischemia. Transl Stroke Res. 2018;9(3):215-22. https://doi.org/10.1007/ s12975-017-0572-0

10. Jayaraj RL, Azimullah S, Beiram R, Jalal FY, Rosenberg GA. Neuroinflammation: friend and foe for ischemic stroke. J Neuroinflammation. 2019;16(1):142. https://doi.org/10.1186/s12974-019-1516-2

11. Radenovic L, Nenadic M, Ulamek-Koziol M, Januszewski S, Czuczwar SJ, Andjus PR, et al. Heterogeneity in brain distribution of activated microglia and astrocytes in a rat ischemic model of Alzheimer's disease after 2 years of survival. Aging (Albany NY). 2020;12(12):12251-67. https://doi. org/10.18632/aging.103411

12. Jian Z, Liu R, Zhu X, Smerin D, Zhong Y, Gu L, et al. The Involvement and Therapy Target of Immune Cells After Ischemic Stroke. Front Immunol. 2019;10:2167. https://doi.org/10.3389/ fimmu. 2019.02167

13. Wattananit S, Tornero D, Graubardt N, Memanishvili T, Monni E, Tatarishvili J, et al. MonocyteDerived Macrophages Contribute to Spontaneous Long-Term Functional Recovery after Stroke in Mice. J Neurosci. 2016;36(15):4182-95. https://doi.org/10.1523/JNEUROSCI.4317-15.2016

14. Becerra-Calixto A, Cardona-Gomez GP. The Role of Astrocytes in Neuroprotection after Brain Stroke: Potential in Cell Therapy. Front Mol Neurosci. 2017;10:88. https://doi.org/10.3389/fnmol.2017.00088

15. Patel AR, Ritzel R, McCullough LD, Liu F. Microglia and ischemic stroke: a double-edged sword. Int J Physiol Pathophysiol Pharmacol. 2013;5(2):73-90.

16. Pope A, Nixon RA. Proteases of human brain. Neurochem Res. 1984;9(3):291-323. https://doi. org/10.1007/BF00963980

17. Davis M, Mantle D, Mendelow AD. The role of proteolytic enzymes in focal ischaemic brain damage. Acta Neurochir Suppl. 2000;76:261-4. https://doi.org/10.1007/978-3-7091-6346-7_53

18. Zhao BQ, Tejima E, Lo EH. Neurovascular proteases in brain injury, hemorrhage and remodeling after stroke. Stroke. 2007;38(2 Suppl):748-52. https://doi.org/10.1161/01.STR.0000253500.32979.dl

19. Morancho A, Rosell A, Garcia-Bonilla L, Montaner J. Metalloproteinase and stroke infarct size: role for anti-inflammatory treatment? Ann N Y Acad Sci. 2010;1207:123-33. https://doi. org/10.1111/j.1749-6632.2010.05734.x

20. Curcio M, Salazar IL, Mele M, Canzoniero LM, Duarte CB. Calpains and neuronal damage in the ischemic brain: The swiss knife in synaptic injury. Prog Neurobiol. 2016;143:1-35. https://doi. org/10.1016/j.pneurobio.2016.06.001

21. Akpan N, Troy CM. Caspase inhibitors: prospective therapies for stroke. Neuroscientist. 2013;19(2):129-36. https://doi.org/10.1177/1073858412447875

22. Yadati T, Houben T, Bitorina A, Shiri-Sverdlov R. The Ins and Outs of Cathepsins: Physiological Function and Role in Disease Management. Cells. 2020;9(7). https://doi.org/10.3390/cells9071679

23. Bright NA, Davis LJ, Luzio JP. Endolysosomes Are the Principal Intracellular Sites of Acid Hydrolase Activity. Curr Biol. 2016;26(17):2233-45. https://doi.org/10.1016/j.cub.2016.06.046

24. Campden RI, Zhang Y. The role of lysosomal cysteine cathepsins in NLRP3 inflammasome activation. Arch Biochem Biophys. 2019;670:32-42. https://doi.org/10.1016/j.abb.2019.02.015

25. Vidak E, Javorsek U, Vizovisek M, Turk B. Cysteine Cathepsins and their Extracellular Roles: Shaping the Microenvironment. Cells. 2019;8(3). https://doi.org/10.3390/cells8030264

26. Fonovic M, Turk B. Cysteine cathepsins and extracellular matrix degradation. Biochim Biophys Acta. 2014;1840(8):2560-70. https://doi.org/10.1016/j.bbagen.2014.03.017

27. Stoka V, Turk V, Turk B. Lysosomal cysteine cathepsins: signaling pathways in apoptosis. Biol Chem. 2007;388(6):555-60. https://doi.org/10.1515/BC.2007.064

28. Liu CL, Guo J, Zhang X, Sukhova GK, Libby P, Shi GP. Cysteine protease cathepsins in cardiovascular disease: from basic research to clinical trials. Nat Rev Cardiol. 2018;15(6):351-70. https://doi. org/10.1038/s41569-018-0002-3 
29. Zhang X, Luo S, Wang M, Shi GP. Cysteinyl cathepsins in cardiovascular diseases. Biochim Biophys Acta Proteins Proteom. 2020;1868(4):140360. https://doi.org/10.1016/j.bbapap.2020.140360

30. Gu YH, Kanazawa M, Hung SY, Wang X, Fukuda S, Koziol JA, et al. Cathepsin L acutely alters microvessel integrity within the neurovascular unit during focal cerebral ischemia. J Cereb Blood Flow Metab. 2015;35(11):1888-900. https://doi.org/10.1038/jcbfm.2015.170

31. Fukuda S, Fini CA, Mabuchi T, Koziol JA, Eggleston LL, Jr., del Zoppo GJ. Focal cerebral ischemia induces active proteases that degrade microvascular matrix. Stroke. 2004;35(4):998-1004. https:// doi.org/10.1161/01.STR.0000119383.76447.05

32. Costa AG, Cusano NE, Silva BC, Cremers S, Bilezikian JP. Cathepsin K: its skeletal actions and role as a therapeutic target in osteoporosis. Nat Rev Rheumatol. 2011;7(8):447-56. https://doi.org/10.1038/ nrrheum.2011.77

33. Gondi CS, Rao JS. Cathepsin B as a cancer target. Expert Opin Ther Targets. 2013;17(3):281-91. https://doi.org/10.1517/14728222.2013.740461

34. Palermo C, Joyce JA. Cysteine cathepsin proteases as pharmacological targets in cancer. Trends Pharmacol Sci. 2008;29(1):22-8. https://doi.org/10.1016/j.tips.2007.10.011

35. Kos J, Mitrovic A, Mirkovic B. The current stage of cathepsin B inhibitors as potential anticancer agents. Future Med Chem. 2014;6(11):1355-71. https://doi.org/10.4155/fmc.14.73

36. Hashimoto Y, Kakegawa H, Narita Y, Hachiya Y, Hayakawa T, Kos J, et al. Significance of cathep$\sin B$ accumulation in synovial fluid of rheumatoid arthritis. Biochem Biophys Res Commun. 2001;283(2):334-9. https://doi.org/10.1006/bbrc.2001.4787

37. Yoshifuji H, Umehara H, Maruyama H, Itoh M, Tanaka M, Kawabata D, et al. Amelioration of experimental arthritis by a calpain-inhibitory compound: regulation of cytokine production by E-64-d in vivo and in vitro. Int Immunol. 2005;17(10):1327-36. https://doi.org/10.1093/intimm/dxh311

38. Canbay A, Guicciardi ME, Higuchi H, Feldstein A, Bronk SF, Rydzewski R, et al. Cathepsin B inactivation attenuates hepatic injury and fibrosis during cholestasis. J Clin Invest. 2003;112(2):152-9. https://doi.org/10.1172/JCI200317740

39. Van Acker GJ, Saluja AK, Bhagat L, Singh VP, Song AM, Steer ML. Cathepsin B inhibition prevents trypsinogen activation and reduces pancreatitis severity. Am J Physiol Gastrointest Liver Physiol. 2002;283(3):G794-800. https://doi.org/10.1152/ajpgi.00363.2001

40. Chandran K, Sullivan NJ, Felbor U, Whelan SP, Cunningham JM. Endosomal proteolysis of the Ebola virus glycoprotein is necessary for infection. Science. 2005;308(5728):1643-5. https://doi. org/10.1126/science.1110656

41. Hoegen T, Tremel N, Klein M, Angele B, Wagner H, Kirschning C, et al. The NLRP3 inflammasome contributes to brain injury in pneumococcal meningitis and is activated through ATP-dependent lysosomal cathepsin B release. J Immunol. 2011;187(10):5440-51. https://doi.org/10.4049/ jimmunol.1100790

42. McKerrow JH, Rosenthal PJ, Swenerton R, Doyle P. Development of protease inhibitors for protozoan infections. Curr Opin Infect Dis. 2008;21(6):668-72. https://doi.org/10.1097/ QCO.0b013e328315cca9

43. haitanya GV, Babu PP. Activation of calpain, cathepsin-b and caspase-3 during transient focal cerebral ischemia in rat model. Neurochem Res. 2008;33(11):2178-86. https://doi.org/10.1007/ sl1064-007-9567-7

44. Hill IE, Preston E, Monette R, MacManus JP. A comparison of cathepsin B processing and distribution during neuronal death in rats following global ischemia or decapitation necrosis. Brain Res. 1997;751(2):206-16. https://doi.org/10.1016/S0006-8993(96)01403-5

45. Kilinc M, Gursoy-Ozdemir Y, Gurer G, Erdener SE, Erdemli E, Can A, et al. Lysosomal rupture, necroapoptotic interactions and potential crosstalk between cysteine proteases in neurons shortly after focal ischemia. Neurobiol Dis. 2010;40(1):293-302. https://doi.org/10.1016/j.nbd.2010.06.003

46. Yuan D, Liu C, Wu J, Hu B. Inactivation of NSF ATPase Leads to Cathepsin B Release After Transient Cerebral Ischemia. Transl Stroke Res. 2018;9(3):201-13. https://doi.org/10.1007/ s12975-017-0571-1

47. Nakanishi H. Microglial cathepsin B as a key driver of inflammatory brain diseases and brain aging. Neural Regen Res. 2020;15(1):25-9. https://doi.org/10.4103/1673-5374.264444 
48. Ii K, Ito H, Kominami E, Hirano A. Abnormal distribution of cathepsin proteinases and endogenous inhibitors (cystatins) in the hippocampus of patients with Alzheimer's disease, parkinsonism-dementia complex on Guam, and senile dementia and in the aged. Virchows Arch A Pathol Anat Histopathol. 1993;423(3):185-94. https://doi.org/10.1007/BF01614769

49. Tsujimura A, Taguchi K, Watanabe Y, Tatebe H, Tokuda T, Mizuno T, et al. Lysosomal enzyme cathepsin B enhances the aggregate forming activity of exogenous alpha-synuclein fibrils. Neurobiol Dis. 2015;73:244-53. https://doi.org/10.1016/j.nbd.2014.10.011

50. Hook V, Yoon M, Mosier C, Ito G, Podvin S, Head BP, et al. Cathepsin B in neurodegeneration of Alzheimer's disease, traumatic brain injury, and related brain disorders. Biochim Biophys Acta Proteins Proteom. 2020;1868(8):140428. https://doi.org/10.1016/j.bbapap.2020.140428

51. Wu Z, Ni J, Liu Y, Teeling JL, Takayama F, Collcutt A, et al. Cathepsin B plays a critical role in inducing Alzheimer's disease-like phenotypes following chronic systemic exposure to lipopolysaccharide from Porphyromonas gingivalis in mice. Brain Behav Immun. 2017;65:350-61. https://doi.org/10.1016/j. bbi.2017.06.002

52. Bever CT, Jr., Garver DW. Increased cathepsin B activity in multiple sclerosis brain. J Neurol Sci. 1995;131(1):71-3. https://doi.org/10.1016/0022-510X(95)00039-5

53. Bever CT, Jr., Panitch HS, Johnson KP. Increased cathepsin B activity in peripheral blood mononuclear cells of multiple sclerosis patients. Neurology. 1994;44(4):745-8. https://doi.org/10.1212/ WNL.44.4.745

54. Hook G, Jacobsen JS, Grabstein K, Kindy M, Hook V. Cathepsin B is a New Drug Target for Traumatic Brain Injury Therapeutics: Evidence for E64d as a Promising Lead Drug Candidate. Front Neurol. 2015;6:178. https://doi.org/10.3389/fneur.2015.00178

55. Turk V, Stoka V, Vasiljeva O, Renko M, Sun T, Turk B, et al. Cysteine cathepsins: from structure, function and regulation to new frontiers. Biochim Biophys Acta. 2012;1824(1):68-88. https://doi. org/10.1016/j.bbapap.2011.10.002

56. Petanceska S, Burke S, Watson SJ, Devi L. Differential distribution of messenger RNAs for cathepsins B, L and S in adult rat brain: an in situ hybridization study. Neuroscience. 1994;59(3):729-38. https:// doi.org/10.1016/0306-4522(94)90190-2

57. Cavallo-Medved D, Moin K, Sloane B. Cathepsin B: Basis Sequence: Mouse. AFCS Nat Mol Pages. 2011;2011.

58. Abazeed ME, Blanchette JM, Fuller RS. Cell-free transport from the trans-golgi network to late endosome requires factors involved in formation and consumption of clathrin-coated vesicles. J Biol Chem. 2005;280(6):4442-50. https://doi.org/10.1074/jbc.M412553200

59. Mort JS, Buttle DJ. Cathepsin B. Int J Biochem Cell Biol. 1997;29(5):715-20. https://doi.org/10.1016/ S1357-2725(96)00152-5

60. Repnik U, Cesen MH, Turk B. The endolysosomal system in cell death and survival. Cold Spring Harb Perspect Biol. 2013;5(1):a008755. https://doi.org/10.1101/cshperspect.a008755

61. Bissig C, Hurbain I, Raposo G, van Niel G. PIKfyve activity regulates reformation of terminal storage lysosomes from endolysosomes. Traffic. 2017;18(11):747-57. https://doi.org/10.1111/tra.12525

62. Lie PPY, Nixon RA. Lysosome trafficking and signaling in health and neurodegenerative diseases. Neurobiol Dis. 2019;122:94-105. https://doi.org/10.1016/j.nbd.2018.05.015

63. Saftig P, Klumperman J. Lysosome biogenesis and lysosomal membrane proteins: trafficking meets function. Nat Rev Mol Cell Biol. 2009;10(9):623-35. https://doi.org/10.1038/nrm2745

64. Luzio JP, Hackmann Y, Dieckmann NM, Griffiths GM. The biogenesis of lysosomes and lysosomerelated organelles. Cold Spring Harb Perspect Biol. 2014;6(9):a016840. https://doi.org/10.1101/cshperspect.a016840

65. Yamashiro DJ, Maxfield FR. Kinetics of endosome acidification in mutant and wild-type Chinese hamster ovary cells. J Cell Biol. 1987;105(6 Pt 1):2713-21. https://doi.org/10.1083/jcb.105.6.2713

66. Bombardier JP, Munson M. Three steps forward, two steps back: mechanistic insights into the assembly and disassembly of the SNARE complex. Curr Opin Chem Biol. 2015;29:66-71. https://doi. org/10.1016/j.cbpa.2015.10.003

67. Baker RW, Hughson FM. Chaperoning SNARE assembly and disassembly. Nat Rev Mol Cell Biol. 2016;17(8):465-79. https://doi.org/10.1038/nrm.2016.65 
68. Yoon TY, Munson M. SNARE complex assembly and disassembly. Curr Biol. 2018;28(8):R397-R401. https://doi.org/10.1016/j.cub.2018.01.005

69. Whiteheart SW, Rossnagel K, Buhrow SA, Brunner M, Jaenicke R, Rothman JE. N-ethylmaleimidesensitive fusion protein: a trimeric ATPase whose hydrolysis of ATP is required for membrane fusion. J Cell Biol. 1994;126(4):945-54. https://doi.org/10.1083/jcb.126.4.945

70. Dalal S, Rosser MF, Cyr DM, Hanson PI. Distinct roles for the AAA ATPases NSF and p97 in the secretory pathway. Mol Biol Cell. 2004;15(2):637-48. https://doi.org/10.1091/mbc.e03-02-0097

71. Gomez-Sintes R, Ledesma MD, Boya P. Lysosomal cell death mechanisms in aging. Ageing Res Rev. 2016;32:150-68. https://doi.org/10.1016/j.arr.2016.02.009

72. Akhtar RS, Ness JM, Roth KA. Bcl-2 family regulation of neuronal development and neurodegeneration. Biochim Biophys Acta. 2004;1644(2-3):189-203. https://doi.org/10.1016/j.bbamcr.2003.10.013

73. Groth-Pedersen L, Jaattela M, Nylandsted J. A Method to Monitor Lysosomal Membrane Permeabilization by Immunocytochemistry. Cold Spring Harb Protoc. 2015;2015(10):904-7. https:// doi.org/10.1101/pdb.prot086181

74. Dave Z, Byfield M, Bossy-Wetzel E. Assessing mitochondrial outer membrane permeabilization during apoptosis. Methods. 2008;46(4):319-23. https://doi.org/10.1016/j.ymeth.2008.10.019

75. Hamacher-Brady A, Brady NR. Bax/Bak-dependent, Drpl-independent Targeting of X-linked Inhibitor of Apoptosis Protein (XIAP) into Inner Mitochondrial Compartments Counteracts Smac/ DIABLO-dependent Effector Caspase Activation. J Biol Chem. 2015;290(36):22005-18. https://doi. org/10.1074/jbc.M115.643064

76. Vanwalleghem G, Fontaine F, Lecordier L, Tebabi P, Klewe K, Nolan DP, et al. Coupling of lysosomal and mitochondrial membrane permeabilization in trypanolysis by APOLl. Nat Commun. 2015;6:8078. https://doi.org/10.1038/ncomms9078

77. Amantini C, Morelli MB, Santoni M, Soriani A, Cardinali C, Farfariello V, et al. Sorafenib induces cathepsin B-mediated apoptosis of bladder cancer cells by regulating the Akt/PTEN pathway. The Akt inhibitor, perifosine, enhances the sorafenib-induced cytotoxicity against bladder cancer cells. Oncoscience. 2015;2(4):395-409. https://doi.org/10.18632/oncoscience.147

78. Goyal S, Amar SK, Dubey D, Pal MK, Singh J, Verma A, et al. Involvement of cathepsin B in mitochondrial apoptosis by p-phenylenediamine under ambient UV radiation. J Hazard Mater. 2015;300: 415-25. https://doi.org/10.1016/j.jhazmat.2015.07.032

79. Repnik U, Stoka V, Turk V, Turk B. Lysosomes and lysosomal cathepsins in cell death. Biochim Biophys Acta. 2012;1824(1):22-33. https://doi.org/10.1016/j.bbapap.2011.08.016

80. Wang F, Gomez-Sintes R, Boya P. Lysosomal membrane permeabilization and cell death. Traffic. 2018;19(12):918-31. https://doi.org/10.1111/tra.12613

81. Alu A, Han X, Ma X, Wu M, Wei Y, Wei X. The role of lysosome in regulated necrosis. Acta Pharm Sin B. 2020;10(10):1880-903. https://doi.org/10.1016/j.apsb.2020.07.003

82. Lafrenaye AD, McGinn MJ, Povlishock JT. Increased intracranial pressure after diffuse traumatic brain injury exacerbates neuronal somatic membrane poration but not axonal injury: evidence for primary intracranial pressure-induced neuronal perturbation. J Cereb Blood Flow Metab. 2012;32(10):191932. https://doi.org/10.1038/jcbfm.2012.95

83. Benchoua A, Braudeau J, Reis A, Couriaud C, Onteniente B. Activation of proinflammatory caspases by cathepsin B in focal cerebral ischemia. J Cereb Blood Flow Metab. 2004;24(11):1272-9. https:// doi.org/10.1097/01.WCB.0000140272.54583.FB

84. Seyfried D, Han Y, Zheng Z, Day N, Moin K, Rempel S, et al. Cathepsin B and middle cerebral artery occlusion in the rat. J Neurosurg. 1997;87(5):716-23. https://doi.org/10.3171/jns.1997.87.5.0716

85. Nitatori T, Sato N, Waguri S, Karasawa Y, Araki H, Shibanai K, et al. Delayed neuronal death in the CAl pyramidal cell layer of the gerbil hippocampus following transient ischemia is apoptosis. J Neurosci. 1995;15(2):1001-11. https://doi.org/10.1523/JNEUROSCI.15-02-01001.1995

86. Saido TC, Yokota M. Neurodegenerative diseases as proteolytic disorders: brain ischemia and Alzheimer's disease. Tanpakushitsu Kakusan Koso. 1997;42(14 Suppl):2408-17.

87. Zuo X, Hou Q, Jin J, Chen X, Zhan L, Tang Y, et al. Inhibition of Cathepsins B Induces Neuroprotection Against Secondary Degeneration in Ipsilateral Substantia Nigra After Focal Cortical Infarction in Adult Male Rats. Front Aging Neurosci. 2018;10:125. https://doi.org/10.3389/fnagi.2018.00125 
88. Zuo X, Hou Q, Jin J, Zhan L, Li X, Sun W, et al. Inhibition of Cathepsin B Alleviates Secondary Degeneration in Ipsilateral Thalamus After Focal Cerebral Infarction in Adult Rats. J Neuropathol Exp Neurol. 2016;75(9):816-26. https://doi.org/10.1093/jnen/nlw054

89. Ellis RC, O'Steen WA, Hayes RL, Nick HS, Wang KK, Anderson DK. Cellular localization and enzymatic activity of cathepsin B after spinal cord injury in the rat. Exp Neurol. 2005;193(1):19-28. https://doi.org/10.1016/j.expneurol.2004.11.034

90. Aoki T, Kataoka H, Ishibashi R, Nozaki K, Hashimoto N. Cathepsin B, K, and S are expressed in cerebral aneurysms and promote the progression of cerebral aneurysms. Stroke. 2008;39(9):2603-10. https://doi.org/10.1161/STROKEAHA.107.513648

91. Amantea D, Micieli G, Tassorelli C, Cuartero MI, Ballesteros I, Certo M, et al. Rational modulation of the innate immune system for neuroprotection in ischemic stroke. Front Neurosci. 2015;9:147. https://doi.org/10.3389/fnins.2015.00147

92. Winegar BD, Lansman JB. Voltage-dependent block by zinc of single calcium channels in mouse myotubes. J Physiol. 1990;425:563-78. https://doi.org/10.1113/jphysiol.1990.sp018118

93. Gu WW, Lu SQ, Ni Y, Liu ZH, Zhou XY, Zhu YM, et al. 2-(3',5'-Dimethoxybenzylidene) cyclopentanone, a novel synthetic small-molecule compound, provides neuroprotective effects against ischemic stroke. Neuroscience. 2016;316:26-40. https://doi.org/10.1016/j.neuroscience.2015.11.052

94. Seyfried DM, Veyna R, Han Y, Li K, Tang N, Betts RL, et al. A selective cysteine protease inhibitor is non-toxic and cerebroprotective in rats undergoing transient middle cerebral artery ischemia. Brain Res. 2001;901(1-2):94-101. https://doi.org/10.1016/S0006-8993(01)02289-2

95. Yang D, Han Y, Zhang J, Ding C, Anagli J, Seyfried DM. Improvement in recovery after experimental intracerebral hemorrhage using a selective cathepsin B and L inhibitor. J Neurosurg. 2011;114(4):1110-6. https://doi.org/10.3171/2010.6.JNS091856

96. Zuo X, Hu S, Tang Y, Zhan L, Sun W, Zheng J, et al. Attenuation of secondary damage and Abeta deposits in the ipsilateral thalamus of dMCAO rats through reduction of cathepsin B by bis(propyl)cognitin, a multifunctional dimer. Neuropharmacology. 2020;162:107786. https://doi.org/10.1016/j. neuropharm.2019.107786

97. Gauthier S, Kaur G, Mi W, Tizon B, Levy E. Protective mechanisms by cystatin C in neurodegenerative diseases. Front Biosci (Schol Ed). 2011;3:541-54. https://doi.org/10.2741/s170

98. Ni J, Wu Z, Peterts C, Yamamoto K, Qing H, Nakanishi H. The Critical Role of Proteolytic Relay through Cathepsins B and E in the Phenotypic Change of Microglia/Macrophage. J Neurosci. 2015;35(36):12488-501. https://doi.org/10.1523/JNEUROSCI.1599-15.2015

99. Katunuma N. Posttranslational processing and modification of cathepsins and cystatins. J Signal Transduct. 2010;2010:375345. https://doi.org/10.1155/2010/375345

100. Montaser M, Lalmanach G, Mach L. CA-074, but not its methyl ester CA-074Me, is a selective inhibitor of cathepsin B within living cells. Biol Chem. 2002;383(7-8):1305-8. https://doi.org/10.1515/ BC. 2002.147

101. Wieczerzak E, Rodziewicz-Motowidlo S, Jankowska E, Gieldon A, Ciarkowski J. An enormously active and selective azapeptide inhibitor of cathepsin B. J Pept Sci. 2007;13(8):536-43. https://doi. org/10.1002/psc.883

102. Reich M, Lesner A, Legowska A, Sienczyk M, Oleksyszyn J, Boehm BO, et al. Application of specific cell permeable cathepsin $G$ inhibitors resulted in reduced antigen processing in primary dendritic cells. Mol Immunol. 2009;46(15):2994-9. https://doi.org/10.1016/j.molimm.2009.06.017

103. Cathers BE, Barrett C, Palmer JT, Rydzewski RM. pH Dependence of inhibitors targeting the occluding loop of cathepsin B. Bioorg Chem. 2002;30(4):264-75. https://doi.org/10.1016/ S0045-2068(02)00009-3

104. Sekeljic V, Bataveljic D, Stamenkovic S, Ulamek M, Jablonski M, Radenovic L, et al. Cellular markers of neuroinflammation and neurogenesis after ischemic brain injury in the long-term survival rat model. Brain Struct Funct. 2012;217(2):411-20. https://doi.org/10.1007/s00429-011-0336-7

105. Hatsuta H, Takao M, Nogami A, Uchino A, Sumikura H, Takata T, et al. Tau and TDP-43 accumulation of the basal nucleus of Meynert in individuals with cerebral lobar infarcts or hemorrhage. Acta Neuropathol Commun. 2019;7(1):49. https://doi.org/10.1186/s40478-019-0700-z 
106. van Groen T, Puurunen K, Maki HM, Sivenius J, Jolkkonen J. Transformation of diffuse beta-amyloid precursor protein and beta-amyloid deposits to plaques in the thalamus after transient occlusion of the middle cerebral artery in rats. Stroke. 2005;36(7):1551-6. https://doi.org/10.1161/01. STR.0000169933.88903.cf

107. Li X, Shi MQ, Chen C, Du JR. Phthalide derivative CD21 ameliorates ischemic brain injury in a mouse model of global cerebral ischemia: involvement of inhibition of NLRP3. Int Immunopharmacol. 2020;86:106714. https://doi.org/10.1016/j.intimp.2020.106714 
